\title{
A Salutogenic Mental Health Model: Flourishing as a Metaphor for Good Mental Health
}

\author{
Nina Helen Mjøsund
}

\section{Abstract}

This chapter focuses on a salutogenic understanding of mental health based on the work of Corey Keyes. He is dedicated to research and analysis of mental health as subjective wellbeing, where mental health is seen from an insider perspective. Flourishing is the pinnacle of good mental health, according to Keyes. He describes how mental health is constituted by an affective state and psychological and social functioning, and how we can measure mental health by the Mental Health Continuum-Short Form (MHC-SF) questionnaire. Further, I elaborate on Keyes' two continua model of mental health and mental illness, a highly useful model in the health care context, showing that the absence of mental illness does not translate into the presence of mental health. You can also read about how lived experiences of former patients support Keyes dual model of mental health and mental illness. This model makes it clear that people can perceive they have good mental health even with mental illness, as well as people with perceived poor or low mental health can be without any mental disorder.

\footnotetext{
N. H. Mjøsund ( $₫)$

Division of Mental Health and Addiction, Department of Mental Health Research and Development, Vestre Viken Hospital Trust, Drammen, Norway

e-mail: nina.helen.mjosund@vestreviken.no
}

The cumulative evidence for seeing mental disorder and mental health function along two different continua, central mental health concepts, and research significant for health promotion are elaborated in this chapter.

\section{Keywords}

Mental health - Mental health promotion · Flourishing - Mental health continuum short form $\cdot$ MHC-SF . Two continua model Salutogenesis · Complete mental health Positive mental health · Well-being

\subsection{Introduction}

This chapter is about mental health. Mental health is explained from a salutogenic perspective. This is an asset- and resource-oriented approach, which is explained with Corey Keyes' theoretical model of mental health [1-3], where mental health is understood as the presence of feelings and functioning, and not the absent of illness. The two continua model of mental health $[3,4]$ contributes to an understanding of mental health relevant in health care services by incorporating knowledge about diseases (pathogenesis) and complements this with the knowledge about health and well-being (salutogenesis). 
Years ago, WHO [5] introduced a definition of health praised as well as criticized from many perspectives. However, it can be seen as a definition including situations a person is eager to achieve and situations a person is eager to avoid. "Health is a state of complete physical, mental and social well-being and not merely the absence of disease and infirmity" ([5], p. 1). Health has different meanings to different people. Green and Tones [6] say it so strikingly:

\footnotetext{
...health is one of those abstract words, like love and beauty, that mean different things to different people. However, we can confidently say that health is, and has always been, a significant value in people's lives ([6], p. 8).
}

To focus on mental health by separating it from health in its totality might be artificial due to the risk of losing the sight of health's complexity and composition. Mjøsund et al. [7] argue that perceived mental health, and physical, emotional, social, and spiritual aspects of health reciprocally influence each other. It seems that the phenomenon of mental health is especially fragile from being separated from the totality of health. However, a conscious theoretical attention to one of the aspects of health while remembering its connectedness to the other aspects might facilitate a deeper understanding and more targeted clinical intervention to promote it.

In a society with a dominant awareness on illness and disease prevention, people need useful knowledge to care for and promote their mental health, as well as physical, spiritual, and social health. Academics and scholars need theories and models to study mental health, and health professionals and health promoters need an extensive knowledge base to perform evidence-based interventions for quality enhancement in clinical practices. Scientists claim to adapt a pragmatic approach accepting various conceptualizations of health because it remains unlikely that we arrive at consensus on a health definition for health promotion research [8].

Findings from lived experiences of inpatient care in the project Positive Mental Health-From What to How [9] shed light on some elements of the mental health and Keyes' dual model of mental health [2]. In this qualitative research project, the meanings of mental health and mental health promotion were explored from the perspective of persons with former and recent patient experiences [7].

\subsection{Mental Health}

Nearly two decades ago, Corey Keyes, PhD in sociology [1], suggested to operationalize mental health as a syndrome of symptoms of positive feelings and positive functioning in life. Mental health is about an individual's subjective wellbeing; the individuals' perceptions and evaluations of their own lives in terms of their affective state, and their psychological and social functioning [1]. Inspired by salutogenesis, mental health is viewed as the presence of positive states of human capacities and functioning in cognition, affect, and behavior [3].

Hence, the more dominant view of mental health as the absence of psychopathology was questioned by Keyes [3]. While still holding this view, Keyes needed to employ the DSM-3 [10] approach as a theoretical guide for the conceptualization and the determination of the mental health categories and the diagnosis of mental health [1]. These terms, more often used in diagnosing mental disorders, rather than health, were used with a conscious aim [1, 4, 11]. Keyes chooses to utilize DSM-3, its established reputation and familiarity, as a tool aiming to place the domain of mental health on equal footing with mental illness [1]. The measurement of mental health was done in the same way as psychiatrist measures common mental disorders, as for example a major depressive episode [12]. The concepts (syndromes, symptoms, and diagnosis) are familiar for nurses and for multidisciplinary professionals in health care services, as well as for patients and their relatives, which is a pedagogic beneficial when health promotion models and theories are used to guide interventions in clinical practice.

Mjøsund [9] contributes to the knowledge base of health promotion by investigating experiences of mental health among persons with mental disorders. This study explored how 
mental health was perceived by former patients [7], and the experiences of mental health promotion efforts in an inpatient setting [13]. The methodology Interpretative Phenomenological Analysis [14] was applied on 12 in-depth interviews. Apart from the participants, an advisory team of five research advisors either with a diagnosis or related to a family member with severe mental illness was involved at all stages of the research process as part of the extensive service user involvement applied in the project $[15,16]$.

\subsubsection{Mental Health as a Syndrome of Symptoms}

Keyes [1] operationalizes mental health as a syndrome of symptoms, based on an evaluation or declaration that individuals make about their lives. The syndrome of symptoms of positive feelings and positive functioning in life included psychological, social, and emotional well-being [1], make up the family tree of mental health, which is portrayed in Fig. 5.1.
How you are feeling about life includes (1) emotional well-being - and how you are functioning is about, (2) psychological well-being, and (3) social well-being. The division of subjective well-being consists in this way of two compatible traditions: the Hedonic tradition, focusing on the individual's feelings toward life, and the Eudaimonic tradition that equates mental health with how human potential, when cultivated, results in functioning well in life [3, 17]. Emotional well-being consists of perceptions of happiness, interest in life, and satisfaction with life [18]. Where happiness is about spontaneous reflection on pleasant and unpleasant affects in one's immediate experience, the life satisfaction represents a more long-term assessments of one's life [2]. The Hedonic approach equals emotional well-being as it frames happiness as positive emotions and represent the opinion that a good life is about feeling good or experiencing more moments of good feelings [12]. In contrast to the emotional well-being, psychological well-being is about the individual's self-report about the quality with which they are functioning [2]. Psychological and social well-being are rooted in

Family Tree of Mental Health

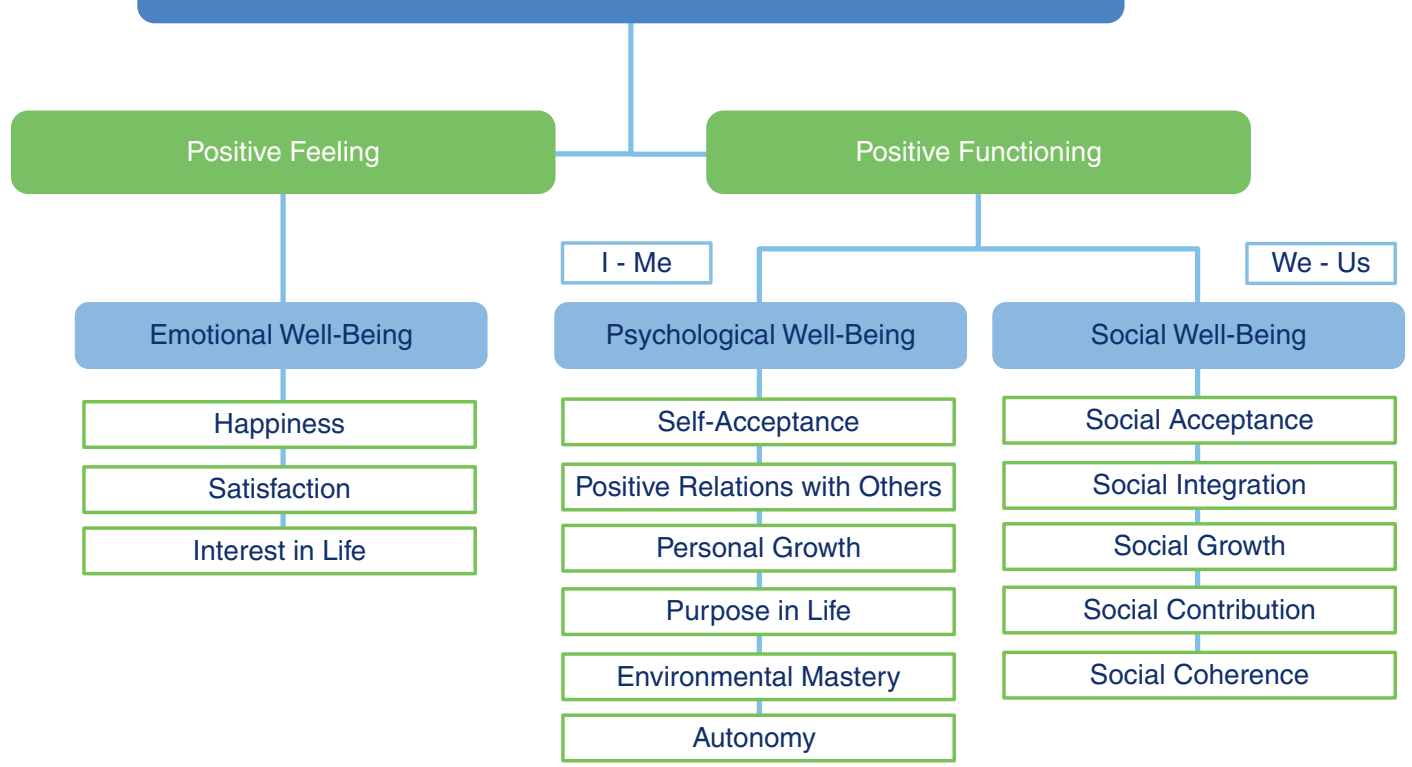

Fig. 5.1 The family tree of mental health. (Reproduced with permission from a lecture given by C. Keyes in Drammen, Norway, 13th of December 2010) 
the Eudaimonic tradition which claims that happiness is about striving toward excellence and positive functioning, both individually and as a member of the society [2]. Eudaimonia frames happiness as a way of doing things in the world and represents the opinion that a good life is about how well individuals cultivate their abilities to function well or to do good in the world [12]. Psychological well-being is conceptualized as a private phenomenon that is focused on the challenges encountered by the individual; it is about how well an individual functions in life [12]. Social well-being represents a more public experience related to the individual social tasks in their social structures and communities [2]. Social well-being is about how well an individual is functioning as a citizen and a member of a community [12]. An important distinction between psychological and social well-being is that the former represents how people view themselves functioning as "I" and "Me," while the latter represents how people view themselves functioning as "We" and "Us" [17].

The level of mental health is indicated when a set of symptoms of emotional well-being combined with symptoms of psychological and social well-being at a specific level are present for a specified duration $[1,2]$. This constellation of symptoms coincides with the individual's internal and subjective judgment of their affective state and their psychological and social functioning.

\subsubsection{Mental Health: From Languishing to Flourishing}

Mental health can be conceptualized along a continuum and subdivided into three conditions or levels: languishing, moderate, and flourishing mental health [1]. To be flourishing is to be filled with positive emotions and to be functioning well psychologically and socially. Flourishing has emerged to be a term describing the optimal state of mental health [19]. Languishing is to be mentally unhealthy, which is experienced as being stuck, stagnant, or that life lacks interest and engagement [2]. Further, languishing can be described as emptiness and lack of progress, the feeling of a quiet despair that parallels accounts of life as hollow, empty, a shell, or a void. Individuals diagnosed as neither flourishing nor languishing are considered to have moderate mental health [1]. To be diagnosed as having flourishing, moderate or languishing mental health, three dimensions or symptoms of emotional well-being, six of psychological wellbeing, and five dimensions of social well-being are assessed [18]. A state of mental health is indicated when a set of symptoms at a specific level are present or absent for a specified duration, and they coincide with distinctive cognitive and social functioning [1].

\subsubsection{Measuring Mental Health: The Mental Health Continuum Short Form}

The self-administered questionnaire Mental Health Continuum-Short Form (MHC-SF) was developed to assess mental health based on individuals' responses to structured scales measuring the presence or absence of positive effects (happiness, interest in life, and satisfaction), and functioning in life, which includes the measurement of the two dimensions: psychological wellbeing and social well-being $[1,18]$. Psychological well-being is characterized by the presence of intrapersonal reflections of one's adjustment to and outlook on life and consists of six dimensions: self-acceptance, positive relations with others, personal growth, purpose in life, environmental mastery, and autonomy. Social well-being epitomizes the more public and social criteria and consists of social coherence, social actualization, social integration, social acceptance, and social contribution [17]. Individuals who are flourishing or languishing must exhibit, respectively, high or low levels on at least seven or more of the dimensions [1]. Keyes [18] explains:

To be diagnosed with flourishing mental health, individuals must experience 'every day' or 'almost every day' at least one of the three signs of hedonic wellbeing and at least six of the eleven signs of 
positive functioning during the past month. Individuals who exhibit low levels (i.e., 'never' or 'once or twice' during the past month) on at least one measure of hedonic wellbeing and low levels on at least six measures of positive functioning are diagnosed with languishing mental health. Individuals who are neither flourishing nor languishing are diagnosed with moderate mental health ([18], p. 1).

The MHC-SF is constructed to be interpreted by both a continuous scoring, sum $0-70$, and a categorical diagnosis of flourishing, moderate mental health or languishing. The questionnaire has been translated to many languages and applied in different cultures across many continents, such as Europe [20], Africa [17], Australia [21], SouthAmerica [22], North-America [23, 24], and Asia $[25,26]$. Recently, the structure and application were evaluated for cross-cultural studies, involving 38 nations [27]. The MHC-SF shows good internal reliability, consistency, and convergent and discriminant validity in respondents between the age of 18 and 87 years [20] and across the lifespan [28]. The MHC-SF is claimed to be valid and reliable for monitoring well-being in student groups [29], as well as in both clinical (affective disorders) and nonclinical groups [30]. Moreover, the MHC-SF has also been used as the outcome in intervention studies [31, 32].

\subsubsection{Flourishing: The Pinnacle of Good Mental Health}

The term flourishing gives associations to something we want to achieve, a state where we are thriving, growing, and unfolding, and I have vitality, energy, and strength. The concept of flourishing has mostly been used in the field of positive psychology and sociology. Although the concept is considered to be relevant in nursing practice and research, it is still virtually absent in the nursing literature [19]. According to Keyes, flourishing is the pinnacle of good mental health; he chose to use the term flourishing to be clear that he was talking about mental health and not merely the absence of mental illness [12]. An evolutionary concept analysis of flourishing claimed that flourishing is still an immature concept, however with a growing evidence of flourishing as a district concept [19]. This concept analysis was based on four common conceptual frameworks of flourishing. The framework with most information available and most cited was presented by Keyes [1]. Additionally, the frameworks of Diener and Diener et al. [33, 34], Huppert and So [35], and Seligman [36] were included in this concept analysis [19]. The authors request further multidisciplinary research to establish standard operational and conceptual definitions and to develop effective interventions [19].

\subsubsection{Perceived Mental Health: A Dynamic Movement on a Continuum}

Former inpatients described mental health as an ever-present aspect of life; moreover, mental health was perceived as a dynamic phenomenon, a constantly ongoing movement, or process like walking up or down a staircase [7]. The movement was affected by experiences in the emotional, physical, social, and spiritual domains of life and accompanied by a sense of energy. Figure 5.2 shows that mental health is expressed both verbally and by body language, and in everyday life, mental health was experienced as a sense of energy and as increased or decreased well-being [7].

It is interesting that the participants living with the consequences of severe mental disorders were not talking about the absence of illness, pathological conditions, and disorder symptoms when they described their perception of mental health and mental health promotion [7]. The salutogenic understanding of Keyes [3] claiming that mental health is the presence of feelings and functioning, a state of human capacities, was supported by how the participants perceived mental health.

The understanding of mental health as a process and movement, like walking up or down a spiral staircase-equivalent to a continuum-is previously confirmed by a study of young people [37]. Talking about the experience of being in different positions on the mental health staircase, 


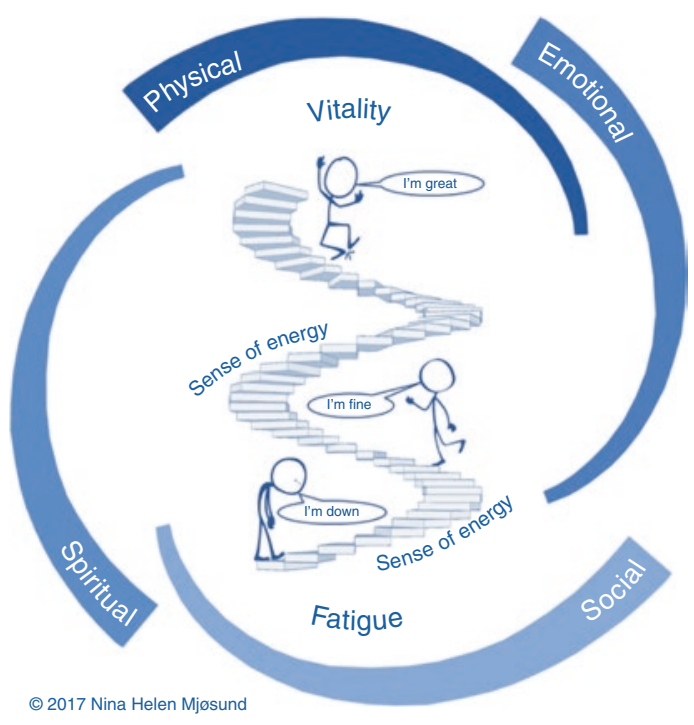

Fig. 5.2 Perceived mental health. (Reproduced with permission from Mjøsund NH. Positive mental health-from what to how. A study in the specialized mental health care service. Trondheim: Norwegian University of Science and Technology, Faculty of Medicine and Health Sciences, Department of Public Health and Nursing; 2017)

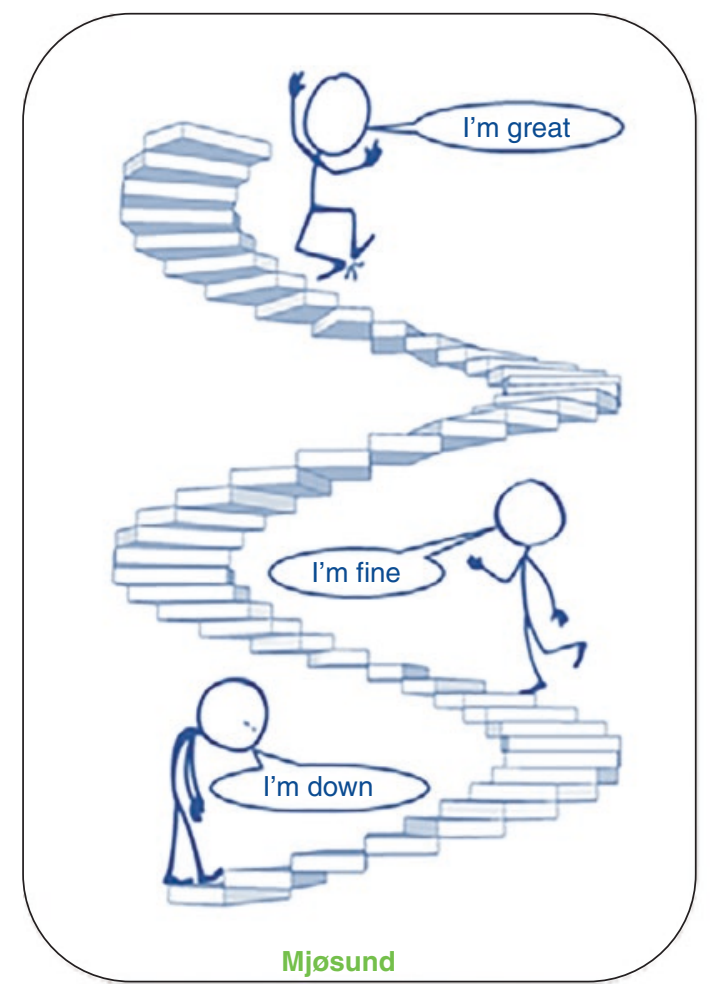

the exploration of the participants' accounts and their descriptions clearly indicated a vertical movement in accordance with Keyes' [1] continuum of mental health. The perception of the phenomenon of mental health as an ever present aspect of life, a part of being human [7], is of significance. Mental health was perceived as a quality of daily life, not characterized by quantitative entities such as numbers, but rather as good or bad, up or down, poor or strong. Mental health being experienced as constantly present in life and a part of being could be a contradiction to the early work of Keyes, when he described flourishing as the presence of mental health and languishing as absence of mental health [1]. More recently, [3, 12, 38] languishing is denoted as the absence of positive mental health or "the lowest level of mental health" [39]. Based on the participants' way of speaking about the position "low in the staircase" [7], and Keyes' description of high, moderate, and low mental health, Fig. 5.3 visualizes the levels of mental health.

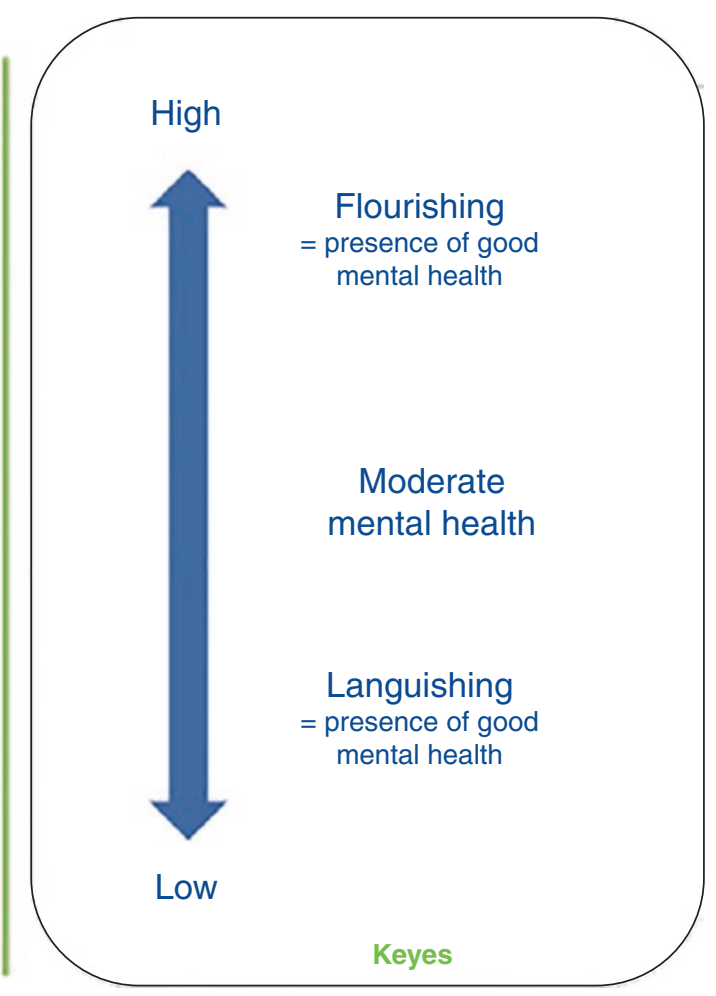

(C) Nina Helen Mjøsund 2021

Fig. 5.3 Mental health as moving up and down a staircase - equivalent to Keyes' continuum of mental health 
Mjøsund et al. [7] claim that a sense of energy was a salient marker of perceived mental health. The sense of energy influenced experiences of mental health in the emotional, physical, spiritual, and relational domains of life. The feeling of energy was proportional with the position on the staircase; while low or down on the staircase, the sense of energy was described as "like starting a shaky engine with a flat battery." The participants described how this lack of mental and physical energy was associated with difficulties initiating and completing any activities [7]. This is in line with Keyes' [1] descriptions of flourishing including the presence of enthusiasm, aliveness, vitality, and an interest in life, associated with a sense of energy. Lack of energy and motivation as a result of mental disorders has been identified by patients as a barrier to integrating healthy lifestyles [40]. An assessment of the sense of energy, in collaboration with the patient, might form the basis for interventions aiming to "push or pull" into an activity or advising rest. Both the interventions have been described by Lerdal [41]. The sense of energy should be investigated more in depth and its relationship with mental health and mental disorders needs further research in order to inform the health promotion knowledge base.

The use of lay language in order to break down barriers between stakeholders in health promotion and health care is encouraged [42]. Having dialogs about taking a step or moving in the staircase of mental health is one way of operationalizing mental health into lay language for all people. Visualizing theoretical models might increase the possibility to grasp the content, as well as the usefulness in clinical practice can be promoted. Illustrations might enhance insight and shared understanding that is significant in health promotion initiatives aiming to increase empowerment (Figs. 5.1, 5.2, 5.3 and 5.4).

\subsection{The Two Continua Model}

The two continua model includes the presence of human capacities and functioning as well as the assessment of disease or infirmity [3, 4]. The contemporary dominant perspective in mental health care is on treating diseases and illness. Therefore, theories, models, and concepts which can help to facilitate mental health promotion are required. The dual continua model includes related but distinct dimensions of both mental health and mental illness [11, 28, 43, 44]. The illustration of the two continua model of health (Fig. 5.4.) reproduced from Keyes [3] visualizes the conceptualized definition of health along the vertical line and the continuum of mental illness along the horizontal line.

This dual model of mental health and mental illness goes well with WHO's [5] definition of health and is particular significant for health professionals in health care settings. The classical myth of Asclepius, the God of Medicine, and his two daughters Hygeia and Panacea gave rise to complementary concepts and approaches to health. The daughters represents two different points of view enlightening the distinction between the definitions of health and illness [6]. The daughter Hygeia represented a salutogenic approach symbolizing the virtue of wise living and well-being. Salutogenesis comes from the Latin word "salus" which means health and is considered as a state of human capacities and functioning. Health is the natural order of things, a positive attribute to which human beings are entitled if they govern their life wisely. Panacea represented the pathogenic approach, which considers health as the absence of disease and illness [3].

With Hygeia and Panacea in mind, it becomes clear that it is possible to have good mental health even with mental illness, and one can have poor or low mental health without mental illness. This concurs with accounts from persons living with mental disorders [7]. In the field of recovery, the influence of positive mental health has been studied in a sample of persons with mood and anxiety disorders [45] and individuals during recovery from drug and alcohol problems [46]. Moreover, the absence of mental illness does not equal the presence of mental health and revealing that the causes of mental health are often distinct from those understood as the causes for mental illness [43], and the conditions that protect against mental disorders do not automatically promote the 


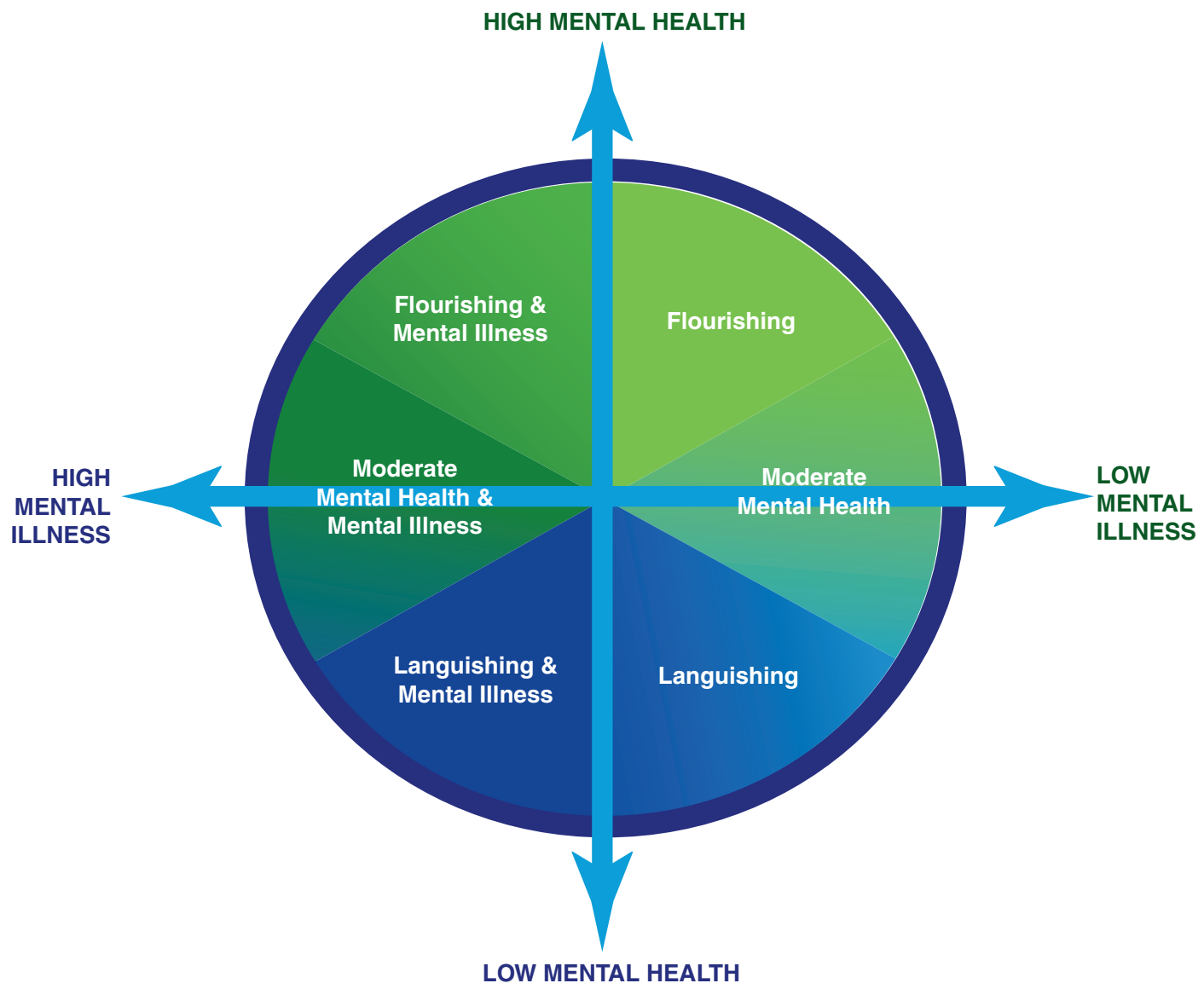

Fig. 5.4 The dual-continua model. (Reproduced with permission from Keyes CLM. Mental Health as a Complete State: How the Salutogenic Perspective Completes the Picture. In: Bauer GF, Hämmig O, editors.

presence of positive mental health [3]. There seems to be cumulating evidence that mental disorders and mental health function along two different continua that are only moderately interrelated [4, 20, 28].

There is a growing interest for studying the relationship between mental health and mental illness in various environments, including work settings and psychosocial work conditions [47]. MHC-SF has been found to be valid and reliable for monitoring well-being in both clinical (patients with affective disorders) and nonclinical samples [30]. The prevalence of flourishing among individuals with schizophrenia spectrum disorders has been studied in Hong Kong [48].
Bridging Occupational, Organizational and Public Health: A Transdisciplinary Approach. London: Springer; 2014. p. 179-92)

Psychiatric outpatients with major mental illness have lower rates of well-being compared to controls, although about one-third is seen to be flourishing [49]. Screening of levels of mental health complements mental disorders screening in the prediction of suicidal behavior and impairment of academic performance among college students [50]. High level of mental health seems to protect against the onset of mental disorders (mood, anxiety, and substance abuse disorders) [51] or function as a resilience resource [52]. A study examined the presence and correlates of wellbeing measured by MHC-SF and psychopathology in a sample of female patients with eating disorders, as well as the level of mental health 
compared with the general population [53]. Less research has been done in treatment settings and hospitals; however, one study provides evidence for the psychometric properties of the MHC-SF in a primary care youth mental health setting, and they claim that the MHC-SF's three-factor structure is valid for use in mental health care [54].

Health promotion in health care should take a holistic approach, also anchored in the WHO's [5] definition of health, meaning the salutogenic orientation complementing the pathogenic orientation in contemporary health care services. I claim that the two continuum model provides theoretical tools which are useful in the development of health promotion interventions in the health care context; this model is equalizing treatment and care of disorders and the promotion of health. Having the dual continua model in mind, the protection of mental health is not to be confused with protections against mental disorders. I would like to emphasize the differentiation between the protection of mental health (something positive) and the protection against mental illness (something negative). The perception of what is positive or negative depends on the context and culture and might differ from one person to another. However, in this chapter, the terms positive and negative are used simply to illustrate the difference in purpose. In clinical practice of health disciplines such as nursing, it is relevant to have theoretical models to guide in customizing the care to the individual situation of the person. Patients and health care providers may utilize this framework to focus on the mental illness status, as well as the persons' level of mental health [44]. Keyes' conceptual framework maps on to themes emerging from narratives about recovery from mental illness [55] and can be a model to bridge mental illness with positive mental health in processes of recovery [56].

The findings presented by Mjøsund et al. [7] give support to the promotion and protection of mental health as described in the two continua model [2], which brings the continuum of mental illness and the continuum of mental health into the same picture (Fig. 5.4). This corresponds to the experiences presented by the participants and interpretation of their accounts led to an under- standing of an everyday life where they perceived illness and health as intertwined, but also dissimilar [7]. They have been diagnosed with a mental disorder, but they are not their diagnosis, life is also mental health and well-being. The recognition of the duality of mental health and mental illness require major changes for current clinical practice in health care dominated by the pathogenic approach. Health promotion and mental health promotion should have a more dominant position in today's health care systems. Complementing health promotion and the protection of good mental health with treatment and prevention against disorder and illness should be given equal consciousness and resources based on the evidence base. In the words of Keyes, "...what lowers the bad does not necessarily increase the good" (Personal communication on 12th of July 2015).

\subsection{Flourishing: Significant in Salutogenic Mental Health Promotion}

Some perspectives on the opportunities and prospects for a further salutogenic development of mental health promotion in the health care might be relevant. In line with Keyes [3], I claim that research using absence of illness as an outcome as well as mental health promotion interventions with a purpose to restore health understood as absent of illness or to protect against disease are wrongly labeled as salutogenic. Even the father of the term salutogenesis, Aaron Antonovsky [57, 58], might be understood as influenced by this way of thinking in some of his writings. In my view, this is the main difference between Antonovsky's salutogenic model of health and Keyes' dual continua model of mental health. Antonovsky gives a conceptual definition of the health ease/dis-ease continuum as a multifaceted state or condition of the human organism:

A person's location at a given point in time, on this continuum, can be described by the person's particular profile on four facets: pain (felt by the individual), functional limitations (felt by the individual), prognostic implications (defined by 
health authorities) and action implication (seen by such authorities as required) ([58], p. 65).

This definition of health leads us to recognize a person's location on the healthy end of continuum, when these negative facets are missing. Based on this, I claim that Antonovsky did not define health as something present or positive, rather the absence of something negative. This is in line with Antonovsky's own remark:

The health ease / dis-ease, or breakdown, continuum as presented here essentially seems to formulate the most desirable health category in negative terms; an absence of pain, no functional limitation, and so forth ([58], p. 67).

In a later paper from 1985, however, Antonovsky defined mental health as somewhat more than the absence of something negative:

Mental health, as I conceive it, refers to the location, at any point in the life cycle, of a person on a continuum which ranges from excruciating emotional pain and total psychological malfunctioning at one extreme to a full, vibrant sense of psychological wellbeing at the other ([59], p. 274).

A salutogenic orientation will focus on the achievement of successful coping, which facilitates movement toward that end of the mental health continuum which is a vibrant sense of psychological well-being. Antonovsky proposed relevant issues and questions to be answered by health promoters. Understanding how people move from the use of unconscious psychological defence mechanism toward the use of conscious coping mechanisms is where the emphasis lies, from rigidity in a defensive structure to the capacity for constant and creative inner readjustment and growth, from a waste of emotional energy toward its productive use, from emotional suffering toward joy, from narcissism toward giving of oneself, and from exploitation of others toward reciprocal interaction [59].

However, it is important to underline that the salutogenic orientation is much more than the salutogenic model of health [60]. Eriksson ([60], p. 103) suggests to use the metaphor of an umbrella to underline that salutogenesis is more than Antonovsky's salutogenic model of health. Salutogenesis is an umbrella concept of theories and concepts about assets for health and wellbeing, including salutogenic elements and dimensions [61]. The editors of The Handbook of Salutogenesis discuss possible futures of the salutogenic orientation, and Georg Bauer states:

If we narrowly follow Antonovsky's conceptualization, salutogenesis is about coping with miserable life situations or about "surviving the toxic river of life" - leaving little space for looking at the bright side of life. Applying salutogenesis to positive health development - or joyful swimming in the river of life - is urgently needed ([60], p. 442).

\subsection{Conclusion}

In summary, I claim that Keyes' model of mental health is an important contribution to the salutogenic orientation and the knowledge base of health promotion. In this model, mental health is defined by the presence of subjective well-being [1], which is in line with the lived experiences of former patients, who perceived mental health as an ever-present aspect of life [7]. Keyes has also given important contribution to the health promotion field by his two continua model of mental health and mental illness in the same context. Splitting the phenomenon of mental health and the phenomenon of mental illness into two separate, although related, phenomena is a meaningful and useful way of understanding health and illness for patients, relatives, and health care professionals in the context of health care services.

\section{Take Home Messages}

- Mental health is an ever-present aspect of life.

- Mental health is about subjective well-being; the individuals' perceptions and evaluations of their own lives in terms of their emotional state and their psychological and social functioning.

- Flourishing, as a term, describes the optimal state of mental health.

- Mental Health Continuum-Short Form (MHC-SF) is a structured scale that can quantify mental health.

- The two continua model of mental health and mental illness includes the presence of human 
capacities and functioning as well as the assessment of disease or infirmity.

- Based on the understanding of mental health and mental illness as two continua, it is possible to have good mental health with mental illness and have poor or low mental health without mental illness.

- The absence of mental illness does not equal the presence of mental health, substantiating that the causes of mental health are often distinct processes from those understood as the risks for mental illness and disorder.

- There is cumulating evidence that mental illness and mental health function along two different continua with only moderate correlation.

- The evidence-based salutogenic models of mental health and the two continua model of mental health and mental illness made by Corey Keyes are significant knowledge for health promotion.

Acknowledgments The author would like to thank Vestre Viken Hospital Trust, Department of Mental Health Research and Development for making it possible to write this chapter. Magnus Lien Mjøsund, thank you for reviewing the language and for assisting in fine-tuning of the figures.

\section{References}

1. Keyes CLM. The mental health continuum: from languishing to flourishing in life. J Health Soc Behav. 2002;43(2):207-22.

2. Keyes CLM. Promoting and Protecting positive Mental health: early and often throughout the lifespan. In: Keyes CLM, editor. Mental well-being: international contributions to the study of positive mental health. Dordrecht: Springer; 2013. p. 3-28.

3. Keyes CLM. Mental health as a complete state: how the Salutogenic perspective completes the picture. In: Bauer GF, Hämmig O, editors. Bridging occupational, organizational and public health: a transdisciplinary approach. London: Springer; 2014. p. 179-92.

4. Keyes CLM. Mental illness and/or mental health? Investigating axioms of the complete state model of health. J Consult Clin Psychol. 2005;73(3):539-48. https://doi.org/10.1037/0022-006X.73.3.539.

5. WHO. WHO definition of Health. Preamble to the Constitution of the World Health Organization as adopted by the International Health Conference, New York, 19-22 June, 1946; signed on 22 July 1946 by the representatives of 61 States and entered into force on 7 April 1948. ed: Official Records of the World Health Organization, no. 2, p. 100; 1946.

6. Green J, Tones K. Health promotion: planning and strategies. Los Angeles: Sage; 2010.

7. Mjøsund NH, Eriksson M, Norheim I, Keyes CLM, Espnes GA, Vinje HF. Mental health as perceived by persons with mental disorders-an interpretative phenomenological study. Int J Ment Health Promot. 2015;17(4):215-33. https://doi.org/10.1080/1462373 0.2015 .1039329 .

8. Mittelmark MB, Bull T. The salutogenic model of health in health promotion research. Glob Health Promot. 2013;20(2):30-8. https://doi. org/10.1177/1757975913486684.

9. Mjøsund NH. Positive mental health-from what to how. A study in the specialized mental healthcare service. Trondheim: Norwegian University of Science and Technology, Faculty of Medicine and Health Sciences, Department of Public Health and Nursing; 2017.

10. American Psychiatric Association. Diagnostic and Statistical Manual of Mental Disorders 3rd ed. Washington, DC: American Psyciatric Assocition. 1987.

11. Keyes CLM. Promoting and protecting mental health as flourishing: a complementary strategy for improving national mental health. Am Psychol. 2007;62(2):95108. https://doi.org/10.1037/0003-066X.62.2.95.

12. Keyes CLM. Why flourishing? In: Harward DW, editor. Well-being and higher education. A strategy for change and the realization of education's greater purpose. Washington, DC: Bridging Theory to Practice; 2016. p. 8.

13. Mjøsund NH, Eriksson M, Espnes GA, Vinje HF. Reorienting Norwegian mental healthcare services: listen to patients' learning appetite. Health Promot Int. 2018;day012:11. https://doi.org/10.1093/ heapro/day012.

14. Smith JA, Flowers P, Larkin M. Interpretative phenomenological analysis: theory, method and research. London: Sage; 2009.

15. Mjøsund NH, Eriksson M, Espnes GA, HaalandØverby M, Jensen SL, Norheim I, et al. Service user involvement enhanced the research quality in a study using interpretative phenomenological analysis: the power of multiple perspectives. J Adv Nurs. 2017;73(1):265-78. https://doi.org/10.1111/ jan. 13093.

16. Mjøsund NH, Eriksson M, Haaland- Øverby M, Jensen SL, Kjus S, Norheim I, et al. Salutogenic service user involvement in nursing research: a case study. J Adv Nurs. 2018;74(9):2145-56. https://doi.org/10.1111/ jan. 13708.

17. Keyes CLM, Wissing M, Potgieter JP, Temane M, Kruger A, Van Rooy S. Evaluation of the mental health continuum-short form (MHC-SF) in setswana-speaking south Africans. Clin Psychol Psychother. 2008;15(3):181-92. https://doi. org/10.1002/cpp.572. 
18. Atlanta: Brief description of the mental health continuum short form (MHC-SF) [database on the Internet]. 2009. https://www.aacu.org/sites/default/files/MHCSFEnglish.pdf. Accessed 25 Oct 2019.

19. Agenor C, Conner N, Aroian K. Flourishing: an evolutionary concept analysis. Issues Ment Health Nurs. 2017;38(11):915-23. https://doi.org/10.1080/016128 40.2017.1355945.

20. Lamers SM, Westerhof GJ, Bohlmeijer ET, ten Klooster PM, Keyes CLM. Evaluating the psychometric properties of the mental health continuum-short form (MHC-SF). J Clin Psychol. 2011;67(1):99-110. https://doi.org/10.1002/jclp.20741.

21. Hides L, Quinn C, Stoyanov S, Cockshaw W, Mitchell T, Kavanagh DJ. Is the mental wellbeing of young Australians best represented by a single, multidimensional or bifactor model? Psychiatry Res. 2016;241:17. https://doi.org/10.1016/j.psychres.2016.04.077.

22. Lupano Perugini ML, de la Iglesia G, Castro Solano A, Keyes CLM. The Mental Health Continuum-short form (MHC-SF) in the Argentinean context: confirmatory factor analysis and measurement invariance. Eur J Psychol. 2017;13(1):93-108. https://doi. org/10.5964/ejop.v13i1.1163.

23. Orpana H, Vachon J, Dykxhoorn J, Jayaraman G. Measuring positive mental health in Canada: construct validation of the Mental Health Continuumshort form. Health Promot Chronic Dis Prev Can. 2017;37(4):123-30. https://doi.org/10.24095/ hpcdp.37.4.03.

24. Gallagher MW, Lopez SJ, Preacher KJ. The hierarchical structure of well-being. J Pers. 2009;77(4):1025-50. https://doi. org/10.1111/j.1467-6494.2009.00573.x.

25. Guo C, Tomson G, Guo J, Li X, Keller C, Söderqvist F. Psychometric evaluation of the Mental Health Continuum-short form (MHC-SF) in Chinese adolescents - a methodological study. Health Qual Life Outcomes. 2015;13(1):198. https://doi.org/10.1186/ s12955-015-0394-2.

26. Rogoza R, Truong Thi KH, Różycka-Tran J, Piotrowski J, Żemojtel-Piotrowska M. Psychometric properties of the MHC-SF: an integration of the existing measurement approaches. J Clin Psychol. 2018;74(10):174258. https://doi.org/10.1002/jclp.22626.

27. Żemojtel-Piotrowska M, Piotrowski JP, Osin EN, Cieciuch J, Adams BG, Ardi R, et al. The mental health continuum-short form: the structure and application for cross-cultural studies-a 38 nation study. J Clin Psychol. 2018;74(6):1034-52. https://doi. org/10.1002/jclp.22570.

28. Westerhof GJ, Keyes CLM. Mental Illness and Mental health: the two continua model across the lifespan. J Adult Dev. 2010;17(2):110-9. https://doi. org/10.1007/s10804-009-9082-y.

29. Johnson BA, Riley JB. Psychosocial impacts on college students providing mental health peer support. J Am Coll Health. 2019:1-5. https://doi.org/10.1080/0 7448481.2019.1660351.

30. Ferentinos P, Yotsidi V, Porichi E, Douzenis A, Papageorgiou C, Stalikas A. Well-being in patients with affective disorders compared to nonclinical participants: a multi-model evaluation of the Mental Health Continuum-short form. J Clin Psychol. 2019;75(9):1585-612. https://doi.org/10.1002/ jclp. 22780.

31. Fledderus M, Bohlmeijer ET, Smit F, Westerhof GJ. Mental health promotion as a new goal in public mental health care: a randomized controlled trial of an intervention enhancing psychological flexibility. Am J Public Health. 2010;100(12):2372. https://doi. org/10.2105/AJPH.2010.196196.

32. Santini ZI, Meilstrup C, Hinrichsen C, Nielsen L, Koyanagi A, Krokstad S, et al. Formal volunteer activity and psychological Flourishing in Scandinavia: findings from two cross-sectional rounds of the European social survey. Soc Curr. 2018;6(4):2329496518815868. https://doi.org/10.1177/2329496518815868.

33. Diener E. The science of Well-being: the collected works of Ed Diener. Social indicators research series 37. New York: Springer Science \& Business Media; 2009.

34. Diener E, Wirtz D, Tov W, Kim-Prieto C, Choi DW, Oishi S, et al. New Well-being measures: short scales to assess flourishing and positive and negative feelings. Soc Indic Res. 2010;97(2):143-56. https://doi. org/10.1007/s11205-009-9493-y.

35. Huppert FA, So TTC. Flourishing across Europe: application of a new conceptual framework for defining well-being. Soc Indic Res. 2013;110(3):837-61. https://doi.org/10.1007/s11205-011-9966-7.

36. Kobau R, Seligman MEP, Peterson C, Diener E, Zack MM, Chapman D, et al. Mental health promotion in public health: perspectives and strategies from positive psychology. Am J Public Health. 2011;101(8):e1-9. https://doi.org/10.1177/10253823 050120020103x.

37. Shucksmith J, Spratt J, Philip K, McNaughton R. A critical review of the literature on children and young people's views of the factors that influence their mental health. Edinburgh: NHS Health Scotland; 2009.

38. Keyes CLM. Mental well-being: international contributions to the study of positive mental health. Dordrecht: Springer; 2013.

39. Iasiello M, van Agteren J, Keyes CLM, Cochrane EM. Positive mental health as a predictor of recovery from mental illness. J Affect Disord. 2019;251:22730. https://doi.org/10.1016/j.jad.2019.03.065.

40. Verhaeghe N, De Maeseneer J, Maes L, Van Heeringen C, Annemans L. Health promotion in mental health care: perceptions from patients and mental health nurses. J Clin Nurs. 2013;22:1569-78. https:// doi.org/10.1111/jocn.12076.

41. Lerdal A. A concept analysis of energy. Its meaning in the lives of three individuals with chronic illness. Scand J Caring Sci. 1998;12(1):3-10.

42. International Health Promotion Hospitals and Health Services. The New Haven recommendations on partnering with patients, families and citizens to enhance performance and quality in health promoting hospitals and health services clinical. Health Promot. 2016;6(1):1-15. 
43. Keyes CLM, Dhingra SS, Simoes EJ. Change in level of positive mental health as a predictor of future risk of mental illness. Am J Public Health. 2010;100(12):2366-71. https://doi.org/10.2105/ AJPH.2010.192245.

44. Keyes CLM. The next steps in the promotion and protection of positive mental health. Can J Nurs Res. 2010;42(3):17-28.

45. Schotanus-Dijkstra M, Keyes CLM, de Graaf R, ten Have M. Recovery from mood and anxiety disorders: the influence of positive mental health. J Affect Disord. 2019;252:107-13. https://doi.org/10.1016/j. jad.2019.04.051.

46. McGaffin BJ, Deane FP, Kelly PJ, Ciarrochi J. Flourishing, languishing and moderate mental health: prevalence and change in mental health during recovery from drug and alcohol problems. Addict Res Theor. 2015;23(5):351-60. https://doi.org/10.3109/16 066359.2015.1019346.

47. Fan JK, Mustard C, Smith PM. Psychosocial work conditions and mental health: examining differences across mental illness and well-being outcomes. Ann Work Expos Health. 2019;63(5):546-59. https://doi. org/10.1093/annweh/wxz028.

48. Chan RCH, Mak WWS, Chio FHN, Tong ACY. Flourishing with psychosis: a prospective examination on the interactions between clinical, functional, and personal recovery processes on wellbeing among individuals with schizophrenia spectrum disorders. Schizophr Bull. 2018;44:778-86. https:// doi.org/10.1093/schbul/sbx120.

49. Stanga V, Turrina C, Valsecchi P, Sacchetti E, Vita A. Well-being in patients with schizophrenia, mood and personality disorders attending psychiatric services in the community. A controlled study. Compr Psychiatry. 2019;91:1-5. https://doi.org/10.1016/j. comppsych.2019.02.001.

50. Keyes CLM, Eisenberg D, Perry GS, Dube SR, Kroenke K, Dhingra SS. The relationship of level of positive mental health with current mental disorders in predicting suicidal behavior and academic impairment in college students. J Am Coll Health. 2012;60(2):126-33. https://doi.org/10.1080/0744848 1.2011.608393.

51. Schotanus-Dijkstra M, ten Have M, Lamers SMA, de Graaf R, Bohlmeijer ET. The longitudinal relationship between flourishing mental health and incident mood, anxiety and substance use disorders. Eur J Public Health. 2017;27(3):563-8. https://doi.org/10.1093/ eurpub/ckw202.

52. Trompetter HR, de Kleine E, Bohlmeijer ET. Why does positive mental health buffer against psychopathology? An exploratory study on self-compassion as a resilience mechanism and adaptive emotion regulation strategy. Cogn Ther Res. 2017;41(3):459-68. https://doi.org/10.1007/s10608-016-9774-0.

53. de Vos JA, Radstaak M, Bohlmeijer ET, Westerhof GJ. Having an eating disorder and still being able to flourish? Examination of pathological symptoms and well-being as two continua of mental health in a clinical sample. Front Psychol. 2018;9:2145. https://doi. org/10.3389/fpsyg.2018.02145.

54. Donnelly A, O'Reilly A, Dolphin L, O'Keeffe L, Moore J. Measuring the performance of the Mental health continuum-short form (MHC-SF) in a primary care youth mental health service. Ir J Psychol Med. 2019;36(3):201-5. https://doi.org/10.1017/ ipm.2018.55.

55. Slade M. Mental illness and well-being: the central importance of positive psychology and recovery approaches. BMC Health Serv Res. 2010;10(1):26. https://doi.org/10.1186/1472-6963-10-26.

56. Provencher HL, Keyes CLM. Complete mental health recovery: bridging mental illness with positive mental health. J Public Ment Health. 2011;10(1):57-69. https://doi.org/10.1108/17465721111134556.

57. Antonovsky A. Unraveling the mystery of health: how people manage stress and stay well. San Francisco: Jossey-Bass; 1987.

58. Antonovsky A. Health, stress, and coping. San Francisco: Jossey-Bass; 1979.

59. Antonovsky A. The life cycle, mental health and the sense of coherence. Isr J Psychiatry Relat Sci. 1985;22(4):273-80.

60. Mittelmark MB, Sagy S, Eriksson M, Bauer GF, Pelikan JM, Lindström B, et al. The handbook of Salutogenesis. Cham: Springer International Publishing AG; 2017.

61. Lindström B, Eriksson M. The Hitchhiker's guide to salutogenesis: salutogenic pathways to health promotion. Helsinki: Folkhälsan; 2010.

Open Access This chapter is licensed under the terms of the Creative Commons Attribution 4.0 International License (http://creativecommons.org/licenses/by/4.0/), which permits use, sharing, adaptation, distribution and reproduction in any medium or format, as long as you give appropriate credit to the original author(s) and the source, provide a link to the Creative Commons license and indicate if changes were made.

The images or other third party material in this chapter are included in the chapter's Creative Commons license, unless indicated otherwise in a credit line to the material. If material is not included in the chapter's Creative Commons license and your intended use is not permitted by statutory regulation or exceeds the permitted use, you will need to obtain permission directly from the copyright holder.

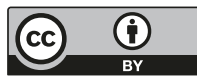

